\title{
Determination of the Momentum of Droplets Impinging on the Pool during Aluminium GMAW
}

\author{
(Determinação do Momentum das Gotas Impingindo sobre a Poça durante Soldagem GMAW de Alumínio)
}

\author{
Américo Scotti ${ }^{l}$, Carlos Eduardo Aguiar Lima Rodrigues ${ }^{l}$ \\ ${ }^{1}$ Universidade Federal de Uberlândia, Faculdade de Engenharia Mecânica, Laprosolda, Uberlândia, MG, Brazil, ascotti@ufu.br
}

\begin{abstract}
The purpose of this work was to raise the kinematics and dynamics characteristics of the droplets under transference during aluminium GMA welding and quantify the partial effect of the momentum on the weld bead formation. It is initially claimed that a better way of quantifying this effect would be through the mass flow rate of the droplets reaching the weld pool; calculated parameter denominated here as Effective Momentum. Bead-on-plate GMAW, shielded with Ar, was carried out using an aluminium alloy wire. Three levels of current and two levels of arc length were employed in the experimental design. High-speed filming shadowgraphy, synchronized with the electrical signals, was used as measuring tool. Dedicated computational programs were employed to quantify arc lengths and size, frequency, acceleration and speed of the droplets. It was confirmed that in spite of the low values of the Effective Momentum for aluminium GMAW, the momentum is one of the governing factor in developing bead penetration. The interaction between Effective Momentum and welding current and its effect on the aluminium GMAW bead geometry is discussed.
\end{abstract}

Key-words: Physics of Welding Arc; momentum; metal transfer; aluminium

Resumo: $O$ objetivo deste trabalho foi o de levantar as características cinemáticas e dinâmicas das gotas em transferência durante a soldagem de alumínio pelo processo GMAW e quantificar o efeito parcial do momentum sobre a formação do cordão. Foi inicialmente atribuído que a melhor maneira de se quantificar este efeito seria através do fluxo de massa das gotas alcançando a poça de fusão, parâmetros calculando e denominado aqui como Momentum Efetivo. Foram realizadas soldagens de simples deposição sobre chapa, protegidas por Ar, usando-se um arame de liga de alumínio. Três níveis de corrente e 2 níveis de comprimento de arco foram empregados no planejamento experimental. Perfilografia com filmagem em alta velocidade, sincronizada com os sinais elétricos, foi usada como método de medida. Programas computacionais dedicados foram usados para quantificar o comprimento de arco e tamanho, freqüência, aceleração e velocidade das gotas. Confirmou-se que, apesar dos baixos valores de Momentum Efetivo alcançados na soldagem GMAW de alumínio, momentum é um dos fatores governantes na penetração do cordão. A interação entre Momentum Efetivo e corrente de soldagem e seus efeitos sobre a geometria do cordão são discutidos.

Palavras-chave: Física do Arco; momentum; transferência metálica; Alumínio

\section{Introduction}

Metal transfer and its relationship with the operational characteristics of the GMAW process is a subject well explored by welding developers and of high interest of welding users. A phenomenon, which has been intensively studied, yet not utterly clarified for GMAW, is the effect of the droplet under transfer on the bead formation. In this context, the welding group of the Universidade Federal de Uberlândia, Brazil, started a research program to give some new insights on this matter. In a previous work [1], it was proposed and assessed a parameter that claims to properly quantify the effect of the droplets reaching the pool over the bead penetration during GMAW. It was concluded

(Recebido em 29/07/2009; Texto Final em 18/11/2009). that the proposed parameter, so-called "Effective Momentum" (see item 2), is the one which better represents the action of the droplets over bead formation.

Preceding the above mentioned work, Essers and Walter [2], in 1981, pointed out in an article, based on experimental data, that there is a correlation between droplet impulse and depth of penetration. Two years later, Waszink and Graat [3] published practical results to show that the speed in which the droplets arrives to the weld pool, which is a component of their momentum, is affected by the acceleration caused by the gas flow in the arc. At the end of the 80's, Mazumder and Tekriwal [4] took advantage of that knowledge and developed a model to predict bead penetration, in which they entered the effect of the droplets and of the heat convection in it. Kim and $\mathrm{Na}$ [5], in 1995, in the same direction, but with more computational resources, considered the filler metal deposition in their model for predicting bead formation, but only estimating (not measuring) the mass, speed and impingement rate of the droplets into the 
weld pool. In the end of the 90's decade, Murray and Scotti [6], in a dimensionless analysis approach, evaluated the importance of the droplets under transfer on the bead penetration in stainless steel plates. They confirmed and quantified the effect of the detaching droplet momentum, which was enough to take energy to the bottom of the pool.

Wang and Tsai [7], in the beginning of the $21^{\text {st }}$ century, calculated the dimensions of the weld pool through the calculation of its temperature distribution caused by the combination of droplet impulse and electromagnetic, surface tension and gravitational forces. Two years later, Kim and collaborators [8] described the heat flow and thermal cycles in T-joint GMAW by using a 3-dimensional model. In that study, the metallic droplets were considered as volumetric sources of heat. The authors calculated the kinematic characteristics of the metal transfer, such as droplet acceleration. Yet in the beginning of 2000, Fan and Kovacevic [9] considered in their numeric model for GMAW, the complementary effects of heat transfer and gas flow in the arc and mass transfer from the electrode as a whole, but they also included the effect of droplets reaching the pool. These researchers used experimental data on metallic transfer to refine their models. Hu and Tsai $[10,11]$ recently presented results of their arc and metal transfer modelling with premises similar to the Fan and Kovacevic's (they also used the same experimental data).

As seen, there is recognition of the importance of the droplet energy delivered to the weld pool. However, the mentioned models present several limitations (these models might be unable to consider all of the contour conditions, governing phenomena and intrinsic characteristics of the metallic transfer). Besides the restricted computational resources in the past, the laboratorial conditions for raising validation data on metallic transfer were very limited. In other words, there were great contributions considering the specificity of each case, but it has not been possible yet to find generic models. One of the reasons is that these models work either neglecting or just estimating the kinematics and dynamics of the droplets in transfer, such as arrival speed to the pool and momentum of the droplets. On the other hand, reasonably recent improvements of techniques for arc visualization and electric signal monitoring and treatment have made possible important increments to the knowledge on this matter, maintaining the importance of continuing experimental studies on metallic transfer. In a recent paper [12], the authors evaluated a methodology to raise kinematic and dynamic characteristics of the droplets under transfer. With the use of these characteristics, a parameter denominated "Effective Momentum" was proposed to represent the action of the droplets over bead formation. The validation of this parameter was carried out in another publication [1], using plain carbon steel electrode (AWS ER70S6). Important validation data results are claimed to have been provided for welding metal transfer modellers. But, in contrast to carbon steel, no experimental data about the momentum effect of aluminium and its alloys have been reported in the current literature. It is important to recall that aluminium alloys present physical characteristics, such as specific mass and electrical and thermal resistivities, remarkably different (lower values) than for steels.
In this context, the objective of this paper was to determine kinematics (speed and acceleration) and dynamics (momentum) characteristics of the droplets in transfer during Aluminium GMAW and quantify the final effect of Momentum on bead formation. The final target is the support to researchers for creating more comprehensive pieces of modelling, since metal transfer data for more reliable validations would be available. There is no claim, however, in predicting weld penetration through droplet momentum.

\section{The Concept of Effective Momentum}

The proposed parameter to compute the momentum effect on bead formation considered a droplet-in-transfer characterization (geometric and kinematic). Knowing the droplet diameter (consequently the mass) and its speed when impinging on the pool surface, it is possible to determine the main dynamic characteristic of the droplets that could influence the bead formation, i.e., the Momentum, as stated by Equation 1:

$$
M=\rho \pi \frac{d^{3}}{6} S_{\text {arrival }} \quad\left[\mathrm{kgms}^{-1}\right]
$$

where " $M$ " is the Momentum, " " the metal density, "d" the droplet diameter and " $\mathrm{S}_{\text {arrival }}$ " the mean speed of droplet arrival on the welding pool, in SI units.

In this paper, it is assumed that a better physical representation of the droplet (movement of mass intermittently) action on the weld pool would be the product of the Momentum by the frequency (f) in which the droplets reach the pool. This parameter is represented by Equation 2 and it was denominated here as Momentum Rate $\left(\mathrm{M}_{\text {rate }}\right)$. As the unit indicates, $\mathrm{M}_{\text {rate }}$ is the force in which the droplets hit the fused metal.

$$
M_{\text {rate }}=M f \quad[N]
$$

However, as $\mathrm{M}_{\text {rate }}$ is a discrete force, the effect of the droplets on the pool would be translated by the time that this force is acting on a same area. Thus, if this mentioned quantity is divided by the welding travel speed (TS), one reaches the parameter that in this work was denominated Effective Momentum (Me), as defined by Equation 3 (as the unit indicates, Me would represent the mass flow rate of the droplets reaching fused metal, but, especially because mass flow rate does not take necessarily into account the droplet size, the denomination proposed in this work aims to emphasize the mass $\mathrm{x}$ speed effect).

$$
M e=\frac{\rho \pi d^{3} S_{\text {arrival }} f}{6 T S} \quad\left[\mathrm{kgs}^{-1}\right]
$$

It is considered in this paper that the Effective Momentum of the droplets is the parameter that explains the capacity of these droplets in contributing for the bead penetration (and other geometric parameters of the bead). 


\section{Experimental Methodology}

The experimental methodology of this work was based on the fact that the welding parameter setting affects the kinematics (speed and acceleration) and dynamics (momentum) of the droplets under transfer. However, to reach the objectives of this work, the experiments must search for the droplet delivering energy in such a way to isolate other variables effects or make them constant. Thus, experiments to guarantee comparisons between beads were planned to consider an interactive effect of the welding current $(I)$ and the arc length $(a)$, but under the same amount of deposited material (same pool volume, since the welding speed (TS) was correspondingly increased to maintain constant its relationship to the wire feed speed (WFS)). By setting current at different values, it would also be varying the metal transfer mode. In addition, while maintaining concomitantly the same amount of deposited material (and approximately the same heat input), one would be trying to minimize the effect of other governing parameters on the bead formation. As a result, the effect of the Momentum of the droplets impinging on the pool could be better distinguished.

However, there was still the need to keep the WFS constant for each current setting, since it is believed that the initial speed of the droplet, which would be equal (or similar, in the case of short-circuiting transfer) to the WFS, would affect the Momentum. Because of this, it was also sought in the experimental methodology to maintain for each current value the same WFS, independently of the arc length. This achievement was possible by using an electronic power source working at constant current mode and imposing a WFS that would match the setting current. Finally, to reach different arc lengths without affecting both current level and WFS, the contact tip-to-work distance $(C T W D)$ setting was systematically varied.

The characterization of the droplet transfer is made through the geometric (droplet diameter and arc length) and kinematic (frequency and body speed) characteristics (the same procedure that the previous work [12] used, including the acknowledgment of the error contained in those procedures).The main tool for this characterization is a synchronized laser shadowgraphy system [13], filming in high-speed (2000 fps, shutter of 1/24000 and resolution of $252 \times 188$ pixels). Additionally, 2 pieces of dedicated software were used for the measurements of the transfer frequency, droplet diameter and arc length $[14,15]$ and of the droplet speed and acceleration (Optimas ${ }^{\circledR} \mathrm{MA}{ }^{\circledR} 1.4$ ). As interest of this study, just the values of the droplets instantaneous arrival speed, obtained through a mean of the last two values obtained with the program, referred here from now on as $S_{a}$ was stipulated.

A wire of the AWS class ER4043, diameter of $1.2 \mathrm{~mm}$, shielded by Ar, was employed at direct current positive electrode (DCEP) condition. Bead-on-plate welds were deposited on Al5000 series plates $(250 \times 6.35 \times 50 \mathrm{~mm})$, in the flat position. A push-pull torch, leaned $15^{\circ}$ forward was used. The currents were set at three different levels, one of them slightly below the transition current (stable globular transfer) and the others above the transition current (stable spray transfers). These welding conditions were replicated in two singular arc lengths, gotten by setting properly the CTWD (18 and $22 \mathrm{~mm}$, respectively for short and long arcs).

Table 1 presents the setting and resultant welding parameters for the experiments. Figure 1 presents typical images, while Table 2 indicates the quantities that characterize the resulting metal transfers. As seen in Figure 1, the metal is transferring in regular spherical droplets and the transition current for changing from globular to spray transfers is just above $130 \mathrm{~A}$. The results shown in this last table seem very coherent with the welding parameter setting (arc length, droplet diameters and transfer frequency). There is no influence of the arc length on the droplet size.

Table 1. Welding parameters.

\begin{tabular}{cccccc}
\hline \multicolumn{2}{c}{ Setting Values } & & \multicolumn{2}{c}{ Monitored Values $^{a}$} \\
\hline $\mathrm{I}_{\text {set }}$ (A) & CTWD (mm) & WFS (m/min) & TS (cm/min) & $\mathrm{I}_{\mathrm{M}}(\mathrm{A})$ & $\mathrm{U}_{\mathrm{M}}(\mathrm{V})$ \\
\hline \multirow{2}{*}{130} & 18 (short arc) & \multirow{2}{*}{5.5} & 38.5 & 139 & 24.9 \\
& 22 (long arc) & & & 136 & 26.2 \\
\multirow{2}{*}{180} & 18 (short arc) & \multirow{2}{*}{7.5} & 52.5 & 181 & 26.0 \\
& 22 (long arc) & & & 183 & 28.3 \\
\multirow{2}{*}{230} & 18 (short arc) & \multirow{2}{*}{9.0} & 63 & 230 & 27.1 \\
& 22 (long arc) & & & 225 & 28.9 \\
\hline
\end{tabular}

${ }^{a}$ Acquisition sampling at $10 \mathrm{kHz}$ and 12 bits, for $5 \mathrm{~s}$ 


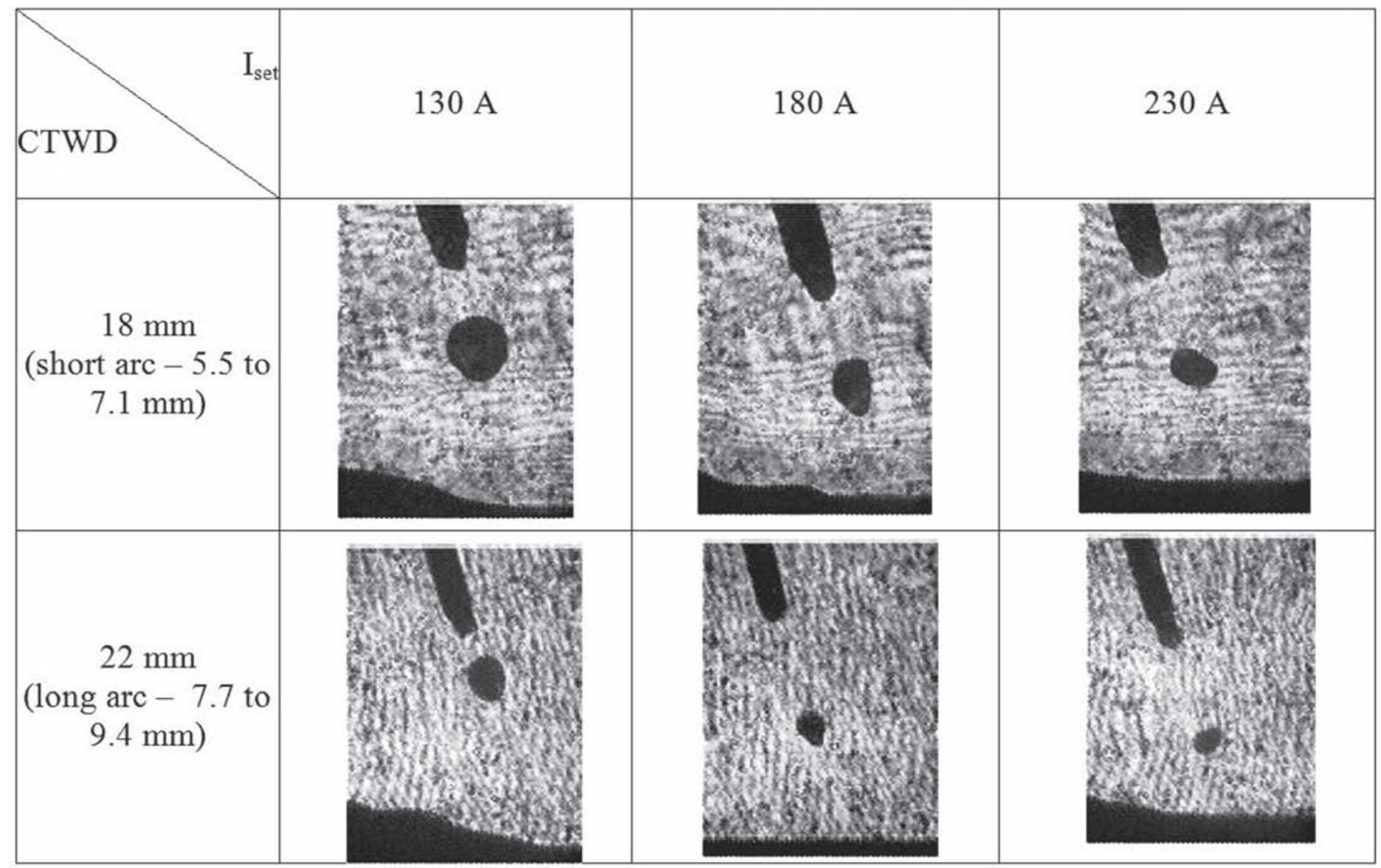

Figure 1. Metal transfers as a function of arc length and welding current (the photos magnifications are different between short and long arcs to emphasize the metal transfer mode).

Table 2. Average values of the arc lengths (a), droplet diameters (d) and respective standard deviations $(\sigma \mathrm{X})$ and of the detachment frequencies (f).

\begin{tabular}{ccccccccc}
\hline Runs & $\mathrm{I}_{\mathrm{SET}}(\mathrm{A})$ & Arc & $\mathrm{a}(\mathrm{mm})$ & $\sigma \mathrm{a}(\mathrm{mm})$ & $\mathrm{d}(\mathrm{mm})$ & $\sigma \mathrm{d}(\mathrm{mm})$ & $\mathrm{f}(\mathrm{Hz})$ & $\mathrm{f}_{\mathrm{EST}}(\mathrm{Hz})$ \\
\hline A & \multirow{2}{*}{130} & short & 6.9 & 0.7 & 1.4 & 0.2 & 77 & 84 \\
B & & long & 8.0 & 0.4 & 1.4 & 0.2 & 78 & 84 \\
C & \multirow{2}{*}{180} & short & 5.5 & 0.6 & 1.2 & 0.1 & 204 & 202 \\
D & & long & 9.4 & 0.7 & 1.1 & 0.1 & 210 & 213 \\
E & \multirow{2}{*}{230} & short & 7.1 & 0.2 & 1.0 & 0.1 & 272 & 336 \\
F & & long & 7.7 & 0.5 & 1.0 & 0.1 & 290 & 336 \\
\hline
\end{tabular}

To confirm the consistence of the measured diameters, an estimate of the detachment frequency $\left(\mathrm{f}_{\mathrm{EST}}\right)$ was made to be compared to the measured metal transfer frequencies (f). This estimation was based on the measured droplet diameters and their standard deviations. The density of the droplets was adopted as $2303 \mathrm{~kg} / \mathrm{m}^{3}$ (Al in liquid state) and the range of expected frequencies for smaller (low frequency) and larger diameters (high frequency) was calculated. It was observed that in all cases the measured frequencies lay between the maximum and minimum of the determined frequency range. However, the measured frequencies were smaller than the estimated frequency using the measured droplet diameter in calculation, in particular to the highest current. One must remember that in these calculations, the metal spattering and evaporation from the electrode was not considered. This finding agrees with the one observed for a carbon steel wire [1], apart from the fact that for this steel wire the difference happened to all currents. An explanation for a slight uneven behaviour between aluminium and steel wires can be grounded in the fact that carbon steel contains gas formers in the composition (more evaporation) and 
it was welded at higher currents. This hypotheses need, however, further validation, but a lack of confirmation does not interfere in the analysis as follows.

\section{Results and Discussion}

\subsection{Assessment of the Droplet Arrival Speed on the Weld Pool Surface $\left(S_{\text {arrival }}\right)$}

Table 3 shows that the more the arc lengths increase and the greater the current level are the higher are the values of $S_{\text {arrival }}$, and the increase of the value is quite significant from globular to spray mode. These results are also in concordance with the ones for a carbon steel wire [1], yet the speeds reached by the aluminium drops (from 1.21 to $2.71 \mathrm{~m} / \mathrm{s}$ ) are a little higher than the speeds met by the steel's (from 0.48 to $1.79 \mathrm{~m} / \mathrm{s}$ ). Naturally, in both cases $\mathrm{S}_{\text {arrival }}$ is much faster than the corresponding WFS (considering the free-flight transfers). Concerning arc lengths, these results are fully justifiable if one uses the concepts of the physics of the arc. It is known that accelerated bodies acquire higher speed if they travel for a larger distance. Besides, the droplets in long arcs take longer time to suffer eventually for a braking action due to metallic vapour coming from the bead pool surface. The higher speeds reached by the aluminium droplets in comparison to steel's, even though the welding currents (pinch effect) were lower, may be due to a higher initial speed (higher WFS), lower density and/or a possible less vapour production at the pool surface (inert shielding gas).

Table 3. Average values and respective standard deviations $(\sigma)$ of the droplet arrival speeds $\left(\mathrm{S}_{\text {arrival }}\right)$.

\begin{tabular}{|c|c|c|c|c|c|c|}
\hline \multirow{2}{*}{$\frac{\text { Current }}{\text { Arc }}$} & \multicolumn{2}{|c|}{130} & \multicolumn{2}{|c|}{180} & \multicolumn{2}{|c|}{230} \\
\hline & short & long & Short & Long & short & long \\
\hline Mean $(\mathrm{m} / \mathrm{s})$ & 1.21 & 1.69 & 2.04 & 2.71 & 2.27 & 2.61 \\
\hline$\sigma$ & 0.15 & 0.30 & 0.28 & 0.19 & 0.12 & 0.24 \\
\hline Level of significance & \multicolumn{2}{|c|}{$\mathrm{P}$-value $<0.01$} & \multicolumn{2}{|c|}{$\mathrm{P}$-value $<0.01$} & \multicolumn{2}{|c|}{ P-value $<0.01$} \\
\hline
\end{tabular}

The explanation for the action of the current is far more complex, due to competitive effects. One should remember that the initial droplet speeds, still forming at the wire tip, are the same for each current level (in other words, the same wire feed speeds), but they become faster for larger currents (higher WFS). In addition to the current-WFS effect on the initial droplet speed, there is also the effect of the forces acting on the droplet (impulse and dragging), also directly proportional to the welding current. If, on the first hand, these current related forces justify a larger acceleration, on the other hand the same current reduces the size of the droplets, as it gets higher. Considering that the plasma jet, in the order of $100 \mathrm{~m} / \mathrm{s}[10,16]$, should have higher speed than the droplets, the dragging force acting on droplets should lead to an increasing $\mathrm{S}_{\text {arrival }}$ for larger droplets, which did not happen. A higher growth of $S_{\text {arrival }}$ from 130 A to 180 is, for sure, related to the droplets sizes (beyond the transition current, the decrease of the droplet with the increasing current is less pronounced, as Table 2 displays).

\subsection{Characterization of the Bead Geometric Parameters}

First of all, the reader must be reminded that when the current was raised, there was a proportional increase of the travel speed (see Table 1). As a result, beads with approximately the same deposited area and the same energy input are expected from the different current-arc length combinations.

Figure 2 illustrates the geometric profiles of the welding beads for the current and arc length combinations. The formation of a slender penetration at the centre of the fused area ("finger like"), as observed in the welds with carbon steel wire [1], is not present here. The "finger-like" characteristic is usually attributed by researchers to a high "momentum" of the droplets, which takes more energy into the bottom of the weld pool [6, 17], when Ar shielding is used. It is believed that a faster heat flow due to the higher thermal conductivity of the aluminium test plate would make the arc thermal effect on the bead formation more efficient than the mechanical effect, making the bead cross section shape more rounded.

From a general view on the results, the higher the current and the longer the arc, the deeper and wider the beads, yet with less reinforcements. A less convex bead (smaller ratio reinforcement by width) is expected from longer arcs. Higher penetration is also expected for increasing current, even if the ratio current by travel speed is kept constant. Similar results were obtained with a carbon steel wire [1]. However, if one considers a free-flight transfer mode (globular or spray), a long arc should lead to shallower penetrations (due to a less concentrated arc connection with the plate), as confirmed in the previous work [1] for a steel wire. This unexpected result would be explained only if another penetration governing parameter (such as oxide forming electron emission sites), would become more significant. However, this parameter was not identified here and deserves further investigation.

\subsection{Momentum of the Droplets under Transference}

From the theory, one could expect that penetration is directly related to heat input. But penetration may become shallower if the pool is too voluminous at a given heat input. Experimental studies show that current itself, even keeping the same relation WFS/TS, seems to augment the penetration too. Yet from the theory, one can suppose that the energy of the 


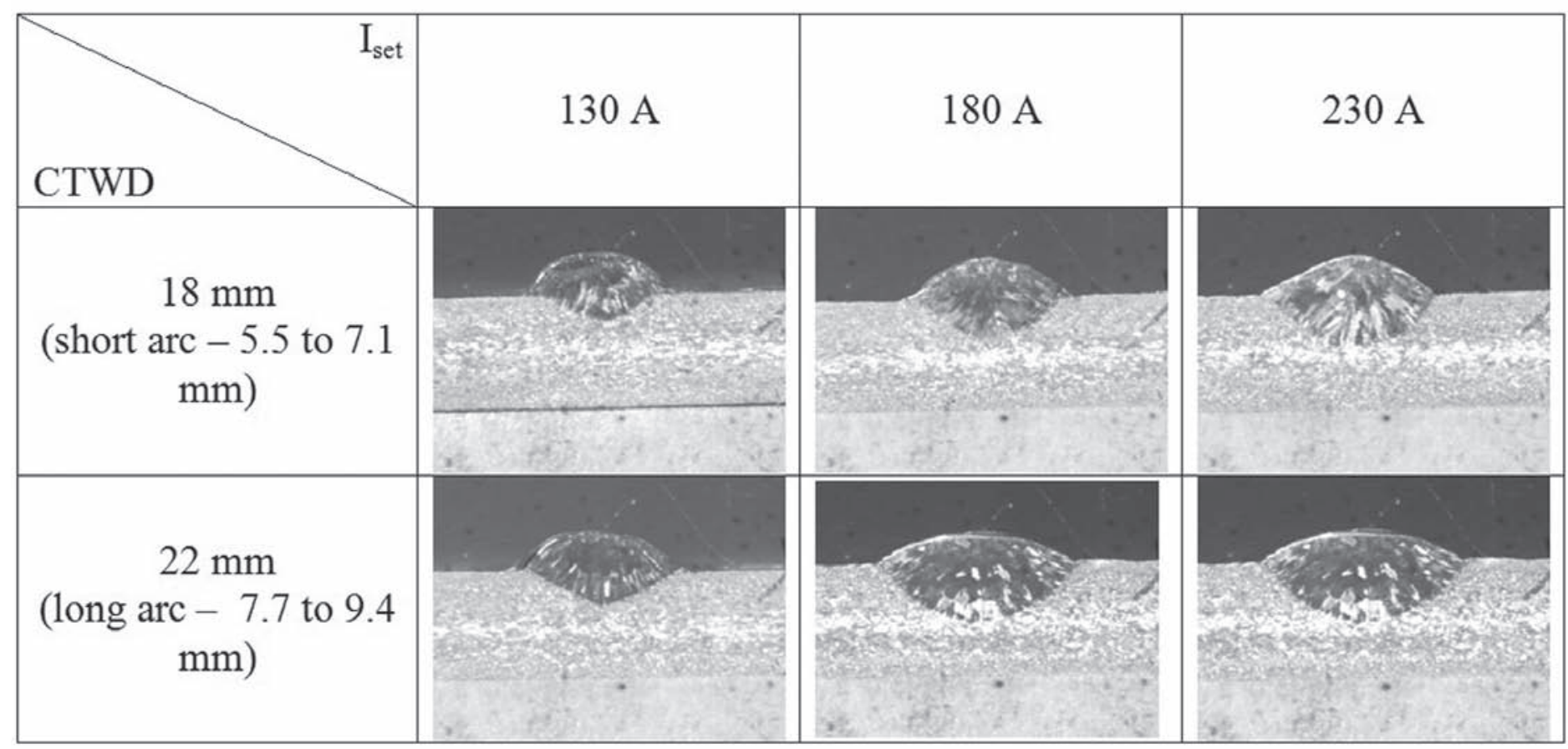

Figure 2. Geometric profile of the beads as a function of arc length and welding current.

droplets impinging into the pool (momentum) will contribute to penetration. It is important to recall that the objective of the experimental planning was to emphasize the individual effect of the momentum, through isolation of the heat input and pool dimension effects. This was reasonably possible in the course of the settings of the travel speed as proportional to the wire feed speed, which in turn is in phase to the welding current (thus, the heat input would be approximately the same, regardless $\left.I_{S E T}\right)$.

Table 4 presents the calculated values for the Effective Momentum $(\mathrm{Me})$, as defined by Equation 3, while Figure 3 relates these values with bead penetration (analog graphic for carbon steel wire is placed beside the one for aluminium for comparison purpose). From Table 4, one can see that penetration increases as $M e$ increases up to around $0.09 \mathrm{~kg} / \mathrm{s}$, but a peculiar behaviour takes place around this value (the increase of $\mathrm{Me}$ does not correspond any longer to further deeper penetration). Observing Table 4, it is possible to verify that the lowest values of $M e$ happen at current of $130 \mathrm{~A}$, but the highest values of $M e$ happen for $180 \mathrm{~A}$, rather than for $230 \mathrm{~A}$. It is well known that current plays the most important role in welding bead formation, justifying higher penetration at an intermediate value of $\mathrm{Me}$. Thus, a concurrent balance of effects (current x $M e$ ) may clarify this unexpected reduction in penetration as $M e$ increases.

Table 4. Average values of the Momentum related parameters of the droplets.

\begin{tabular}{ccccccc}
\hline Runs & $\mathrm{I}_{\mathrm{SET}}(\mathrm{A})$ & Arco & $\mathrm{d}(\mathrm{mm})$ & $\mathrm{f}(\mathrm{Hz})$ & $\begin{array}{c}\mathrm{S}_{\text {arrival }} \\
(\mathrm{m} / \mathrm{s})\end{array}$ & $\begin{array}{c}\text { Me } \times 10^{-1} \\
(\mathrm{~kg} / \mathrm{s})\end{array}$ \\
\hline A & \multirow{2}{*}{130} & short & 1.4 & 77 & 1.22 & 0.05 \\
B & & long & 1.4 & 78 & 1.68 & 0.07 \\
C & \multirow{2}{*}{180} & short & 1.2 & 204 & 2.04 & 0.09 \\
D & & long & 1.1 & 210 & 2.70 & 0.12 \\
E & \multirow{2}{*}{230} & short & 1.0 & 272 & 2.27 & 0.08 \\
F & & long & 1.0 & 290 & 2.61 & 0.10 \\
\hline
\end{tabular}

Observing Figure 3, it is possible to see the same trend for both aluminium and steel wires concerning the relationship Effective Momentum ( $\mathrm{Me}$ ) and bead penetration. But there are some remarkable differences. The values of $M e$ found for aluminium wire are about 10 times less than for steel (despite density is only one third less), despite the fact that the penetrations reached by both welding material were at the same level. Naturally, the role that Me plays on the pool deepness depends on the characteristics (viscosity, surface tension, etc.) of the melted metal, which actions are difficult to predict. Besides, penetration does not depend only on $M e$, on the contrary, heat input is expected to be the governing parameter [6]. Comparing the welding conditions of the aluminium weldments in this work with the one of the steel weldments [1], the first case used a range of I/TS from 3.4 to $3.7 \mathrm{~A} / \mathrm{cm} / \mathrm{min}$ while for steel was employed a range from 6.0 to $6,9 \mathrm{~A} / \mathrm{cm} / \mathrm{min}$, with higher welding energy. 

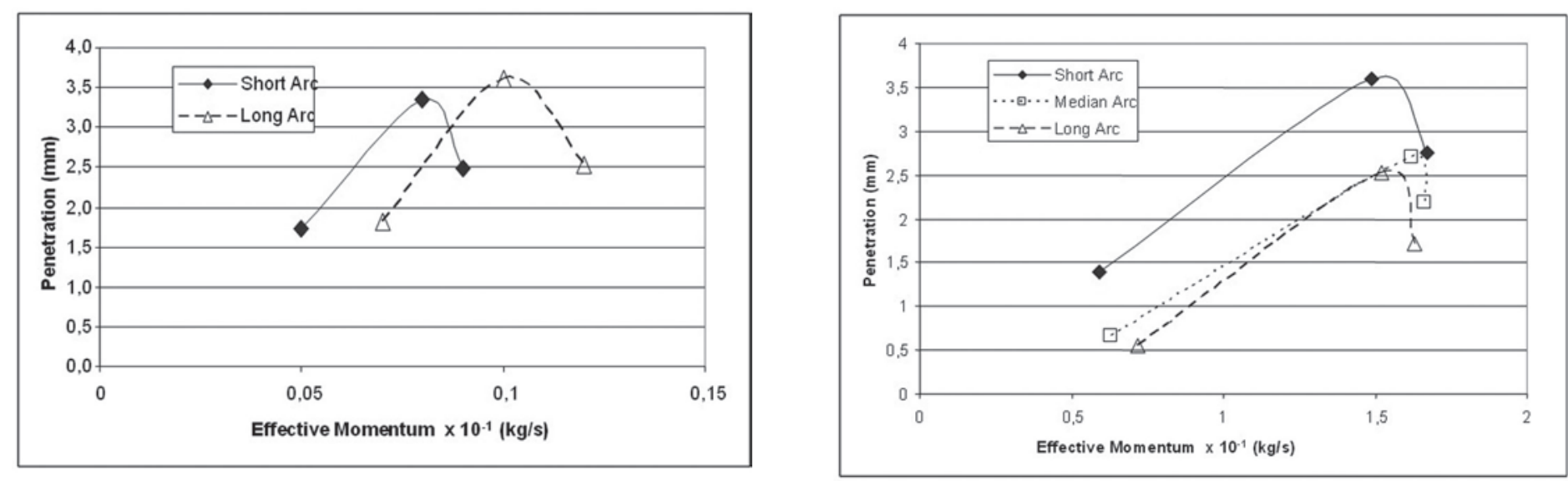

Figure 3. The influence of Effective Momentum on the bead penetration: on the left, using data for Aluminium GMAW (Table 4); on the right, using data for Carbon Steel GMAW (Ref. 1), for comparison purpose.

It can be claimed that a lower point of fusion, despite higher latent heat of fusion and specific heat capacity of the 5000 series aluminium alloy when compared to steel would justify a similar penetration even aluminium presenting lower $M e$ and I/TS ratios. Thus, it is clear by Figure 3 the act of $M e$ on penetration, but this low Me found in aluminium GMAW could justify the lack of "finger like" shape (slender penetration at the centre of the fused area) of the cross sections of the beads, pointed out in item 4.2 as characteristic of carbon steel GMAW shielded with high contents of Ar.

A second difference between aluminium alloy and steel behaviours noted in Figure 3 is that long arc reached the highest $M e$ for aluminium; in contrast to steel weldments (the arc length did not influenced $M e$ for a given current, as seen in ref. 1). This might be an explanation for the higher penetration with long arc (item 4.2). One could state that the welding energy (U $\mathrm{x}$ I/WFS) due to the increased arc voltage (U) for longer arcs would be the reason for that, but it is reasonable to think that this voltage increase would lead to heat losses to the environment, not necessarily to the plate (heat input is not always totally proportional to welding energy). The authors support their hypotheses based on the results for steel. In addition, the authors believe (and plan to demonstrate it) that for aluminium welding the concentration of the arc connection to the plate is not so important for increasing penetration as much it is for carbon steel. This would happen because of the $\mathrm{Al}$ alloys high thermal conductivity. Yarmuch and Patchett [18], for instance, have shown that increasing the time ratio in $\mathrm{CC}+$ in aluminium GTAW the fusion efficiency increases. According to these authors, longer times spent on electrode positive polarity (EP) enhance the area covered by the mobile cathode spots seeking new locations for electron emission. From these comments, one can deduct that a longer EP period makes the arc concentration smaller (the same effect of a long arc).

\section{Conclusions}

By the application of this methodology for determining kinematic and dynamic characteristics of metal transfer in aluminium GMAW (ER4043, $1.2 \mathrm{~mm}$; Ar shielding), with current varying from 130 to $230 \mathrm{~A}$ (metal transfer mode covering from globular to spray), can be deduced that:

- The droplets under transfer reached arrival speeds from 1.21 to $2.71 \mathrm{~m} / \mathrm{s}$, depending on the current level and arc length. These values are much higher than the wire feed speeds, showing that the droplets are accelerated along the arc;

- The longer the arc and the greater the current level the higher the values of the droplet arrival speeds;

- The Effective Momentum cannot be directly related with either droplet mass or individual frequency, as much as for carbon steel (ref 1). The combination of these parameters with arc length, current and travel speed is what makes possible to have higher $M e$ at current values away from the highest;

- The droplet Effective Momentum (the mass flow rate of the droplets reaching fused metal) reached values from 0.05 to $0.12 \mathrm{~kg} / \mathrm{s}$. The value changes accordingly to the metal transfer under a given welding parameter, i.e., the highest current level may not provide the greatest Effective Momentum;

- The low Effective Momentum values found for aluminium GMAW in this work, around 10 times less than for carbon steel GMAW in similar situation, can explain the formation of rounded bead cross sections (avoiding "finger like" shape as observed with steel wires);

- The droplet Effective Momentum shows to play important role in the bead formation (increasing the penetration), but its effect must be analyzed under the influence of the current level too;

- For aluminium, the arc length (indirectly by the diameter, arrival speed and frequency of the droplets), in contrast to for carbon steel, affects the values of the Effective Momentum: a longer arc increases the momentum action of the droplets on the weld pool (this fact help to explain an increasing penetration when the arc is longer);

- The importance of measuring all component parameters of this quantity is highlighted, since the mechanical effect of the droplets impinging into the weld pool was uncovered. 


\section{Acknowledgments}

The authors wish to thank all team members of the welding group Laprosolda (Centre for Research and Development of Welding Processes) of the Universidade Federal de Uberlândia, Brazil, for the infrastructure support and advices. They also thanks to Brazilian bodies for research development, Fapemig (through project TEC 604/2005), for the financial support, and CNPq, for scholarships.

\section{References}

[1] Scotti, A. and Rodrigues, C.E.A.L. Determination of momentum as a mean of quantifying the mechanical energy delivered by droplets during MIG/MAG welding, Eur. Phys. J. Appl. Phys., 45 (1), 2009, 11201, DOI: 10.1051/epjap:2008196 [2] ESSERS, W. G. and WALTER, R., Heat Transfer and Penetration Mechanisms with GMA and Plasma-GMA Welding, Welding Journal, 60 (2), Feb 1981, 37s-42s.

[3] WASZINK, J. H. and GRAAT L. H. J., Experimental Investigation of the Forces Acting on a Drop of Weld Metal. Welding Journal, 62 (4), Abr 1983,109-116.

[4] MAZUMDER, J., TEKRIWAL P., Finite Element Analysis of Three-Dimensional Transient Heat Transfer in GMA Welding. Welding Journal, 67 (6), Jul. 1988, pp 150-156

[5] KIM, J.-W. and NA S.-J., A study of the effect of contact tube-to-workpiece distance on weld pool shape in gas metal arc welding, Welding Journal, 74 (6), Mai 1995, pp. 141-152.

[6] MURRAY, P. E., SCOTTI, A. Depth of penetration in gas metal arc welding, Science and Technology of Welding and Joining, 4 (2), 1999, pp 112-117.

[7] WANG, Y. and TSAI, H.L. Impingement of filler droplets and weld pool dynamics during gas metal arc welding process. International Journal of Heat and Mass Transfer, 44 (11), 2001, pp. 2067-2080

[8] KIM, C.-H., ZHANG, W., DEBROY, T., Modeling of temperature field and solidified surface profile during gas-metal arc fillet welding, Journal of Applied Physics, 94 (4). 2003. pp. 2667-2679.

[9] FAN, H. G. and KOVACEVIC, R., A unified model of transport phenomena in gas metal arc welding including electrode, arc plasma and molten pool. Journal of Physics D: Applied Physics, 37 (18), Sep 2004, pp. 2531-2544

[10] HU, J. and TSAI, H. L., Heat and mass transfer in gas metal arc welding - Part I: The arc. International Journal of Heat and Mass Transfer, 50 (5/6), 2007, pp. 833-846.

[11] HU, J. and TSAI, H. L., Heat and mass transfer in gas metal arc welding - Part II: The metal. International Journal of Heat and Mass Transfer, 50 (5/6), 2007, pp. 808-820.

[12] SCOTTI, A. and RODRIGUES, C.E.A.L., A methodology for Determining Kinematic and Dynamic Characteristics of a Transferring Droplet Aiming Modeling Validation of MIG/MAG Welding, 17th Int. Conf. on Computer Technology in Welding And Manufacturing, TWI, Cranfield, UK, Jun 2008, 11 p.

[13] BÁLSAMO, P.S.S., VILARINHO, L. O., VILELA, M. and SCOTTI, A., Development of an Experimental Technique for Studying Metal Transfer in Welding: Synchronized
Shadowgraphy, The Int. Journal for the Joining of Materials, 12 (1), 2000, 1-12

[14] MAIA, T. C. G., FLÔRES, E. L. and SCOTTI, A., Metal Transfer Quantification in MIG/MAG Process by Image Processing, II Cong. Nacional da Engenharia Mecânica CONEM 2002, João Pessoa, Brasil, UFPB/ABCM, Aug 2002, CPB1200, 10 p. (in Portuguese)

[15] MAIA, T. C. G., FLÔRES, E. L. and SCOTTI, A., Comparative Assessment between Automate and Manual Quantitative Analyses Applied to MIG/MAG Metal Transfer Images, II Cong. Brasileiro de Engenharia de Fabricação - COBEF, Uberlândia, Brazil, Apr 2003, CD ROM (in Portuguese)

[16] JONES, L. A., EAGAR, T. W., LANG, J. H. A dynamic model of drops detaching from a gas metal arc welding electrode. Journal of Physics D: Applied Physics. 31 (1), 1998, pp. 107123.

[17] SCOTTI A.. A review on special metal transfer modes in gas metal arc welding. Journal of Brazilian Society of Mechanical Sciences, 20 (3), 1998, pp. $465-478$.

[18] YARMUCH, M. A. R. and PATCHETT, B.M., Variable AC Polarity GTAW Fusion Behavior in 5083 Aluminum, Welding Journal, AWS, 86 (7), Jul 2007, pp. 196s-200s 